\title{
A colección O Roibén, vieiro de expresión poética do Grupo Bilbao
}

\author{
LUIS LUNA \\ UNED \\ luismiluna@yahoo.es \\ Recibido: junio 2012. Aceptado: agosto 2012
}

\begin{abstract}
Resumo: A colección de cadernos «O Roibén» supón para moitos autores do grupo Bilbao a súa primeira oportunidade de publicación en edicións comerciais, o cal impulsa posteriores publicacións súas nas coleccións maiores de poesía galega contemporánea como Xerais ou Espiral Maior xa integradas nas letras galegas. Ademais, a colección supón tamén a consolidación e a consecuente importancia de cara ao mundo literario galego dun grupo con produción literaria propia fóra das lindes galegas.
\end{abstract}

Palabras clave: poesía galega contemporánea, grupo Bilbao, cadernos, «O Roibén».

\begin{abstract}
The collection of books «O Roibén» represents the first chance to publish commercial editions for many authors belonging to the Bilbao literary group, which favoured further publications in major collections of contemporary Galician poetry such as Xerais or Espiral Maior benchmarks of today's Galician literature. In addition, the collection represented both the consolidation and the consequent importance of a group of writers with their own production in the Galician literary background, given that they wrote and lived outside Galicia.
\end{abstract}

Key words: Galician,contemporary poetry, Bilbao Group, notebooks, «O Roibén»

\section{AS ORIXES DA COLECCIÓN O ROIBÉN}

Aínda que é moi escasa a bibliografía douta -o cal convida a pensar que o fenómeno está insuficientemente estudado- son numerosas as noticias que temos do denominado Grupo Bilbao de escritores galegos en Madrid. Os seus inicios remóntanse segundo os indicios mais fiábeis ao ano 1996, concretamente en novembro, se habemos de facer caso ás anotacións dun dos seus membros máis 
destacados, Vicente Araguas (Frías Conde 2007). A decisión tómase no café Comercial, sito na Glorieta de Bilbao de Madrid. Alá véñense celebrando os famosos faladoiros dos madrigalegos (termo acuñado por Borobó), é dicir dos intelectuais galegos que están de paso por Madrid ou dos que moran habitualmente no rompeondas de todas as Españas. Os faladoiros son o último sábado de cada mes e en elas danse cita estudantes, poetas, artistas, intelectuais, etc...todos eles co propósito de continuar desenvolvendo actividades culturais relacionadas coa cultura galega. Este fenómeno non é novo, se atendemos ao detallado estudo que fai a profesora Ana Cuña (dinamizadora ela mesma dos faladoiros do Comercial e profesora de galego na Universidade Complutense de Madrid durante un dos períodos mais álxidos do Grupo que aquí nos ocupa) dos movementos de intelectuais galegos en Madrid desde os anos 70 no seu xa moi coñecido «prólogo» á antoloxía En tránsito, poesía galega en Madrid ${ }^{1}$ que recolle os nomes mais importantes e os clasifica segundo os movementos e iniciativas que protagonizaron. Mesmo pode irse mais aló, até a época do Rexurdimento pois está documentado o paso por Madrid de Rosalía, Choios Enríquez, Nicomedes Pastor Díaz ou Francisco Añón, amén de outros axitadores culturais galegos non menos importantes.

Daquela, nesa continuación da florecente cultura galega fóra de Galicia que supoñen os faladoiros do café Comercial é onde — baixo a iniciativa de Xavier Frías Conde - se promove a creación dun Grupo Poético que aglutine os creadores que se expresan en lingua galega e moran —ou están de paso- por Madrid. Deciden darlle - a suxestión é de Vicente Araguas—, o nome «Bilbao», debido á localización do café onde se reúnen na Glorieta de Bilbao en Madrid. Comeza un período dourado para as letras galegas na capital de España. Neste primeiro estadio do Grupo atopamos os nomes de Fermín Bouza, Xavier Frías e Vicente Araguas.

Eles son os impulsores de numerosos recitais e presentacións de poetas galegos en Madrid. Para iso contan co apoio de Inés Canosa nese momento responsábel da Libraría-Galería Sargadelos de Madrid e coa inestimábel axuda de Carmen Mejía, profesora do Departamento de Románicas da Universidade Complutense de Madrid. Axiña van darse conta da necesidade de atopar un vieiro de expresión editorial, un selo que os proxecte cara á Galiza interior e poida representalos mais aló do estreito ámbito das letras galegas da capital. Así nace, en 1998, a colección O Roibén ${ }^{2}$ impulsada por Xavier Frías Conde e Rafael Yáñez e á que se unirá posteriormente Luis Luna. Segundo documenta Teresa Seara (2001):

[Asúmese] unha nomenclatura que quere simbolizar unha cor de esperanza noí renacemento dá lingua galega.

\section{e continua dándonos información moi precisa}

Acuña, Ana, «Limiar» en En tránsito, poesía galega en Madrid.

2 Segundo a definición do dicionario da Real Academia Galega, a palabra roibén fai referencia ás nubes de cor vermella que aparecen no horizonte ao abrir do día e ao solpor, e que son sinal de bo tempo, propicio e favorábel. 
Os cadernos do Roibén nacen baixo ou selo editorial de Rio Xuvia para logo, tras dos cinco primeiros números publicados, asumir ou logotipo da Acef (Asociación Celso Emilio Ferreiro) con sede tamén en Madrid.

Como podemos observar, desde o principio os cadernos postúlanse como órgano de expresión do Grupo Bilbao con todo o que este ten de heteroxéneo e provisorio, de pertenza a distintos movementos poéticos e influencias. Trátase, xa que logo, de difundir xeitos moi diversos da poesía galega no exterior e de dar a coñecer as súas distintas expresións. Con ese trazo, a colección pasa por moi diversos momentos que sería interesante estudar dunha maneira ampla e rigorosa. A concreción deste artigo obríganos a adiar tan interesante cuestión para nos centrar en aspectos mais concretos.

\section{A DIFUSIÓN PARCIAL, PRIMEIRAS ANTOLOXÍAS D’O ROIBÉN}

Como é lóxico o primeiro que vai ser publicado na colección $O$ Roibén van ser dúas antoloxías. O primeiro caderno da colección vai ser Carreiros, mostra de poesía da Terra Eo-Navia en lingua galega publicado en maio de 1998 e que recolle a obra de Adela Conde, Crisanto Veiguela e Xavier Frías. Trátase dunha breve antoloxía - xustificada no prólogo debido á dimensión dos cadernos - da obra destes tres poetas publicada xa na revista $O$ Espello e que toma agora forma de libro. Este primeiro caderno ten moi pouca repercusión, se ben constitúe unha das primeiras obras en recoller a interesante variante dialectal do galego que se fala en dita zona raiana.

Máis interesante é o segundo caderno, verdadeira carta de presentación da colección e, por tanto, do grupo Bilbao. Trátase da antoloxía denominada $\mathrm{Co}$ mercial, Poesía Galega en Madrid en que participan Vicente Araguas, Fermín Bouza, Xavier Frías, José Manuel Outeiro, Claudio Pato e Manuel Pereira. Como podemos observar, todos eles son poetas de moi distintas xeracións, con preferencias estéticas diferentes e mesmo con temáticas moi afastadas. Porén, todos eles están unidos por un feito: a súa pertenza ao grupo poético de que estamos a falar. Non en van o volume nace coa intención de: «ser un mostradoiro do que desde a capital de España se está a facer na lingua de Rosalía ${ }^{3} »$.

No prólogo de Comercial, Carmen Mejía ${ }^{4}$ fai unha breve descrición da historia do Grupo e revela dados interesantes sobre a formación do mesmo:

Os compoñentes deste grupo de poetas en galego en Madrid deciden unirse no ano 1996. Na presentación do poemario de Vicente Araguas O gato branco coinciden, falan e deciden facer uns faladoiros non Café Comercial no último sábado de cada mes. E desde aquela até hoxe reúnense co desexo de dar vida á cultura galega en Madrid. Para conseguir o seu obxectivo organizan e participan en recitais de poesía. No ano pasado fixeron un recital non Ateneo de Madrid, este ano participaron Vicente Araguas e Xavier Frías nun recital

\footnotetext{
3 Comercial, contracapa.

4 Ídem, p. 3 (destacado noso).
} 
que con motivo do Dia dás Letras Galegas organizou a Titulación de Filoloxía Románica da Universidade Complutense de Madrid e tamén recitaron na libraría Sargadelos este ano. Doutra banda, crean a Colección O Roibén de poesía. Por tanto, crean o seu propio órgano de expresión aberto a calquera que desexe publicar en galego. Poderiamos dicir que o grupo Bilbao ten o seu funcionamento e que hai un compromiso entre eles e, ao mesmo tempo, reciben a calquera que teña interese pola cultura galega en Madrid.

O compromiso a que fai referencia a prologuista esténdese por Madrid. O activismo dos poetas mencionados e as presentacións do libro van facer que o grupo comece a ser recoñecido e atraia novos membros, case todos eles máis novos e, na súa maioría, poetas. De facto, a poesía vai ser o centro de atención da colección de que vimos falando dado que, até o momento, todos os libros publicados pertencen a este xénero literario. Pensamos que iso se debe a que os membros iniciais do grupo son, ante todo, poetas e buscan a normalización dunha poesía propia, escrita en galego si, pero pertencente por dereito propio ao canon occidental. Trátase de continuar coas liñas que marcan os distintos grupos poéticos de Galiza: conseguir unha poesía variada, de alta calidade estética e editada en perfectas condicións. A ese propósito é ao que se soma, en definitiva, o grupo e a colección que constitúe o seu órgano natural de expresión.

\section{OS PRIMEIROS POEMARIOS}

O ano 1998 vai acabar para a colección coa publicación dun poemario importante para o desenvolvemento literario do grupo Bilbao. Referímonos a Todo morte de Manuel Pereira Valcárcel. Este autor, nado en Ouzande-A Estrada (Pontevedra) en 1955, non coñecía a publicación en edición comercial ${ }^{5}$ antes de publicar Todo morte na nosa colección e vai ser para el un extraordinario punto de inflexión na súa carreira. Begoña Regueiro (2006: 103-113) estudou ben a obra do poeta, cualificándoa de «poesía da experiencia na Galicia actual» co que se insire na tradición literaria mais recente. O libro comeza cunha cita que explica todo o seu contido:

hai días nos que

a vida é

todo morte

A partir de aquí, o libro vai recoller toda unha serie de variacións sobre a morte con un ton elexíaco que recolle o mellor das tradicións galega e castelá e que utiliza frecuentemente recursos da lírica tradicional e medieval como o leixaprén. A terceira parte do libro vai profundar na morte dos seres queridos e en ela descubrimos a verdadeira voz de Pereira, quen introduce a temática amorosa como única posibilidade contra a morte. O erotismo vai ser o predominante no resto da obra de Pereira quen, a partir de aquí, vai introducirse con pleno dereito no mundo da poesía e da intelectualidade galegas. Deste modo ${ }^{6}$, o seu se-

\footnotetext{
5 O seu primeiro libro Poemas de cinza foi publicado en edición de autor en 1990.

6 Trátase de Rosa intima, Espiral Maior, A Coruña, 2000.
} 
guinte libro vai ser editado por unha das coleccións senlleiras da actual edición galega: a editorial Espiral Maior que concentra nas súas páxinas o máis salientábel da poesía galega contemporánea xunto con Xerais.

Eis unha das coordenadas maiores de $O$ Roibén, o servir de plataforma literaria para os autores que publica. Manuel Pereira é aos días de hoxe un autor estudado a nivel académico e un nome de referencia no concernente non só á poesía galega do exterior, mais no que ten que ver coa poesía de temática amoroso-erótica.

Se o ano 1998 significa o ano de inicio da colección (e xa vemos o que comezou), 1999 significa a consolidación e, nomeadamente, o achegamento á mesma de poetas mais novos que se incorporan á dinámica do grupo Bilbao ou que proveñen de Galiza. Este é o caso de Calros Solla (Pontevedra, 1971) que publica Xábregho cun extenso prólogo de Ana Cuña, na altura profesora de lingua galega na Universidade Complutense de Madrid. Para a estudosa, Calros Solla está na mellor liña da poesía anovadora galega que acepta o cripticismo e a vangarda para crear unha linguaxe propia, nova que permita expresar o atávico da terra galega e, asemade, a Galiza moderna ${ }^{7}$. Ana Acuña ${ }^{8}$ definirao así:

Malia a escuridade críptica dalgúns poemas, a súa lectura permitiravos descubrir tesouros agochados (...) Carlos Solla crea outro mundo, o mundo das nosas orixes.

O poemario é en realidade unha antoloxía que recolle textos dos ciclos Ollobecho en off, Calixe, Madre furada e Can Caendo. A súa repercusión en Madrid é intensa, dado que demostra que a poesía galega pode crear unha linguaxe diferente e que, ademais, dialoga coa vangarda e a pos-vangarda, tornándoa radicalmente moderna.

O ano acaba para a colección coa publicación de Xeitos de falar, antoloxía bilingüe galego-asturiana que tenta ampliar a área de influencia da colección.

\section{OS POETAS MOZOS, OS LIBROS COLECTIVOS}

Froito do excelente labor levado a cabo polos membros do Grupo canto á difusión e promoción das letras galegas en Madrid, os poetas mais novos van achegarse ao ámbito da colección, pois supón un altofalante e unha oportunidade de publicación para os seus primeiros poemas, ademais dunha solicitude de apoio deses poetas maiores, xa moi coñecidos, como Vicente Araguas ou Fermín Bouza. Así, no 2000 van publicarse unha rolda xa histórica de cadernos que inauguran a obra poética de autores que na altura (xa en castelán, xa en galego) continuaron co seu labor e conseguiron instalarse como novas (ou xa non tan novas) promesas da poesía actual. Óscar Curieses e Luis Lua publican Hidroemas

\footnotetext{
7 Na liña, por exemplo, do famoso grupo «Rompente».

8 No limiar de Xábregho p. 9
} 
xa baixo o selo de ACEF (Asociación Celso Emilio Ferreiro) e con distribución en España e Portugal ${ }^{9}$.

Hidroemas é unha tensó no sentido tradicional do termo. Os autores interpretan diversos lados do poliedro «auga» desde a súa propia visión e entón reelaboran os poemas para conseguiren a versión final froito xa da estética de ambos. Inicialmente o proxecto común incluía a composición dunha tetraloxía que tocase os catro elementos: auga, lume, ar e terra. Soamente serán publicados dous deles ficando o resto sen facer por esgotamento ou fatiga de materiais. Os poemarios, inicialmente compostos en castelán, son sometidos despois a unha versión en galego, realizada por Luis Luna. A estética de Hidroemas móvese nos eixos da pós-vangarda, tentando que a linguaxe sexa autorreferencial, sen necesidade dun referente historicista ou vivencial. Para Ana Cuña ${ }^{10}$ é

Unha explicación das orixes dende a mitoloxía ata a filosofía (...) cada poema fotografa un EU afogado, un EU nadando contra corrente.

Ademais do valor intrínseco do poemario, o máis interesante do mesmo é que os seus autores son alógrafos, é dicir, poetas que non teñen ningunha vinculación familiar con Galiza e que escollen a lingua galega por predilección. Luis Luna foi quen mais falou desta elección salientando en numerosos recitais que «un non ten que ser de onde nace, senón de onde se sente». Pola súa parte Xavier Frías Conde (2007) tamén se interesou por este fenómeno:

Se trata de un grupo de estudiantes de filología sin vinculación familiar con Galicia que escribieron parte de su obra poética en gallego. Ello fue posible gracias a la labor de Ana Acuña, durante los años que ejerció su docencia del idioma gallego en Madrid.
Algunos de estos jóvenes siguen escribiendo en gallego, combinando su crea- ción literaria con la que realizan en castellano. (...) la calidad de su poesía está fuera de duda tanto en castellano o en gallego (sic), pero resulta chocante en- contrar que este idioma, normalmente reconocido por su lirismo, fue herra- mienta poética para un grupo de personas que llegaron a asumirlo como vehí- culo lingüístico propio

Ademais deste poemario, publícanse Simbiose de Susana González e Victoria Veiguela, Alquimia soñada de Xosé Galán, Onte chovía de Rafael Yáñez e Azul e terra (poesía eonaviega) de Xavier Frías Conde. O primeiro é un libro colectivo de dúas poetas moi distintas entre si que fan un esforzo por realizar unha empresa conxunta, sempre entendendo que os seus poemas van por separado. Susana González (Madrid, 1971) constrúe unha poesía erótica, mesmo de alta voltaxe erótica porque a voz lle sae do sexo do seu eu poético (González \&

9 En Madrid a distribución facíase na Libraría-Galería «Sargadelos» coordinada nese momento por Inés Canosa e que se converteu na sede das presentacións dos cadernos da colección. A respecto de Portugal, o interese de diversos poetas e do selo «Edições Tema» tornará posíbel a venda dos libros e algún lanzamento.

10 Ana Acuña no «Limiar» de Hidroemas. 
Veiguela 2001: 22).

Hoxe teño que falar

Desde o centro do meu ventre

E,

Así verás que teño esa voz profunda que ti esperas.

Victoria Veiguela (León, 1979), pola súa parte, crea unha poesía moito mais reflexiva, insire nunha tradición de poesía feminina de alta estética que reivindica para si un posto na literatura e un estrado desde o que falar. Veiguela, coas súas variantes dialectais eonaviegas, crea un ritmo forte e, asemade, unha voz intensamente persoal e profundamente coral (González + Veiguela 2001: 59):

O meu nome agacha

Moitas mulleres.

Mulleres que fan versos

E que choran

E mulleres que berran

E ouvean á lúa

Xosé Galán (Madrid, 1968) escribe en Alquimia soñada unha poesía de ton reflexivo, moi meditada e medida. Manuel Pereira ${ }^{11}$ exprésao así no limiar que antecede aos poemas:

Hai nesta obra condensación e brevidade. Hai esixencia, imprescindíbel en toda obra literaria, non só poética. E hai pescuda interior, e a relación dese mundo propio co exterior. $\mathrm{O}$ autor procura os extremos para estabelecer despois os niveis de conexión e desencontro.

Rafael Yáñez (Vilalba, 1979) publica o poemario Onte chovía que representa un dos intentos mais conseguidos de todos os cadernos publicados na colección. O verbo de Yáñez é vigoroso, maduro e sobre todo produto dunha linguaxe traballada onde o literario se converte nun reflexo vivido. O poeta entende que entre persoal e o social hai só un paso e a súa morriña se converte en todos os transterrrados, unha realidade moi acusada en Galiza. O eu poético é o neno que se perde no trauma de abandonar a terra natal para se atopar nunha urbe densamente poboada onde todo semella mentira. $\mathrm{O}$ desgarro non se resolve pola poesía, só se mitiga e fica convertido en cicatriz, en costura atrapada en palabras. A expresión de Yáñez conecta co mellor da tradición galega contemporánea e significa, á vez, unha inmersión enxebre no que significa o grupo Bilbao: esa crise que supón manter a propia cultura nun territorio alleo e ás veces ameazante e facelo cunha linguaxe pós-moderna conforme co tempo no que se escribe. Carmen Blanco Ramos ${ }^{12}$ no seu prefacio ao poemario fálanos diso:

\footnotetext{
11 No «Limiar» de Alquimia soñada.

12 No «Limiar»de Onte choveu.
} 
Onte chovía é unha metáfora impresionista vestida de sensacións onde a ollada, dó peregrino poeta, busca vos reflexos dás imaxes para ir xerando cada poema. E todo desde unha óptica vangardista, carente de materialismo e racionalismo.

Para completar os libros do ano 2000, atopamos Azul e terra, poesía eonaviega (1997-1999) de Xavier Frías Conde (Béjar, Salamanca, 1965) a alma da colección que estamos a estudar. Con prólogo de Inma López Silva, narradora e columnista galega, o libro representa ben o que significa o labor dun creador polifacético e auténtico dinamizador da cultura de expresión galega en Madrid. Como el mesmo di nunha autopoética de recente difusión (Frías 2007):

Mi poesía no ha sido nunca una caja de sorpresas. (...) En primer lugar, mi poesía se ha concentrado casi exclusivamente en temas de amor-desamor. No se pueden separar ambas cuestiones, son las dos caras de una misma moneda. Todos mis libros publicados desde el 2000 han seguido esta línea. En segundo lugar, se ha dado en mí una tendencia a la creación de poemas brevísimos, en algunos casos «casi adagios», como los llegó a calificar Vicente Araguas. Esto me llevó a experimentar en algunos casos con formas poéticas como el haiku. Finalmente, una característica de mi poesía es que no solo se expresa en una lengua, sino en varias.

Efectivamente, a poesía de Frías se centra na temática erótica pero sempre como parte dun teatro existencial onde é moi importante o que se cala, ademais que se di. Esa importancia do silencio é a que vai tomar corpo nas formas hiperbreves de que fala o autor. Porque o silencio é necesario para que o erótico se faga, para que a linguaxe poética se realice. Neste libro, o atávico vai ter un papel fundamental nas escenas que se desenvolven:

Quedei a contemplar

silencios e silencios de ti

Lúas

que sen brinde veron

descubrir tous segredos. En vao

podo laiar calquera dos tous nomes,

tantos como as arganas da eira.

Vai calor. O verao anda espido

e folga nos meus beizos.

Silencios...

apenas un escenario improvisado

entre os beizos,

chen, inda, de crenzas

Como vemos, é o «verán nu» o que preside a escena, chegando a ser un personaxe mais que se poetiza. Este atavismo é fundamental para outro poeta do 
grupo Bilbao a quen causa unha morriña especial vivir lonxe da terra mai, da lingua que é para eles matria e espazo simbólico esencial.

Como podemos observar o ano 2000 é importantísimo para a colección. Os cadernos saídos en maio, son reseñados no Correo Galego en decembro por Vicente Araguas no que, sen dúbida, é o apoio definitivo para a colección de cara á literatura galega. Reproducimos a continuación parte do artigo de Araguas (2000) polo valor histórico que representa para os estudosos:

Pois. Volvendo a colección $O$ Roibén, esta deu no mes de marzo cinco novos cadernos (...) Frías escribe dos temas de sempre: amor, nostalxia, terra, amizade con ton abertamente sentimental. Dos seus poemas eu prefiro aqueles que traballan a distancia curta e pequeno formato. (...) Galán, prologado por Manuel Pereira, non se curta á hora de facer unha poesía na que as emocións veñen condicionadas por un xeito de expresión pouco convencional. (...) Luis Miguel Luna (1975) e Óscar A. Curieses (1974) escriben a catro mans Hidroemas, un libro no que a auga, obviamente, vén sendo protagonista esencial. (...) Ben por este dúo que crea beleza. Como o fai Rafael Yáñez (1979) desde presupostos máis tradicionais no libro Onte Chovía que leva prólogo de Carmen Blanco (...) Gústame a poesía de Yáñez, un autor sinxelo pero con trastenda e faiado (...) Finalmente Susana González (1975) e Victoria Veiguela (1979) publican Simbiose (...) Eu aposto por elas, escriban en galego ou, caso de Susana, tamén en romanés. E é que vivimos tempos cosmopolitas. O que está moi ben.

Vicente Araguas, poeta pertencente ao grupo Bilbao encoraxa os xoves a seguiren, a se depuraren, a investigaren no seu modo de dicir, pois é consciente da canteira que se está a formar o redor que el mesmo, xunto con outros poetas, creou. E sabe como non que ese órgano de expresión que é $O$ Roibén ten que seguir adiante, e para iso necesita do apoio e a atención da cultura galega en Galicia.

\section{UN TERCEIRO TEMPO, O DECLIVE DA COLECCIÓN}

Xusto no momento de maior auxe da colección, o traballo e o activismo do grupo Bilbao vai perdendo progresivamente a súa forza orixinaria e vaise disgregando aínda que os faladoiros do café Comercial seguen a ter lugar a cada último sábado de mes. Como se despois de ter atinxido o cumio houbese que facer o descenso, $O$ Roibén comeza a súa última época. Muda de formato e de forma. Dos vellos cadernos azuis pásase a un deseño máis novidoso e empréndense novos proxectos editoriais mais coidados e completos.

O ano 2001 é aínda un ano moi fecundo para a colección que engrosa os seus títulos con novos textos. Calros Solla publica Terras raras que, ademais dos poemas, inclúe fotografías a toda cor, postas, dito isto como curiosidade, para que se clarifique o agarimo posto na colección, a man por amigos da mesma. As fotografías recollen óleos de F. Subtil sobre paisaxes de Cerdedo. O libro constitúe unha magnífica mostra que podería ter sido a colección de seguir adiante. 
Xavier Frías Conde publica Canto de Nedara, insistindo en formas e maneiras e consolidando a súa voz poética. Pola súa banda, Rafael Yáñez publica Lembranzas e olvidos dun estraño con prólogo de Vicente Araguas, quen, como vimos, xa recoñecera a valía deste xove poeta. Victoria Veiguela publica $O$ ouvido e o calado con prólogo de Carmen Mejía. Como vemos, a colección vai tomando corpo, vai tendo o apoio crítico que merece.

Novos nomes súmanse á tarefa. Así Covadonga D’lom publica $A$ soidade dos números primos con prólogo de Xavier Frías ${ }^{13}$ quen explica a nova incorporación facendo fincapé na orixe diversa da escrita poética da autora:

Covadonga D'Lom ten nome asturiano (porque é de orixe asturiana), leva un apelido irlandés por mor dun devanceiro dá Illa de Eire, naceu en Madrid e escrebe en galego.

É interesante seguir ese prólogo de X. Frías ${ }^{14}$ porque efectúa paralelismos entre a poesía que se publica en Madrid e a que se está a escribir en Galiza no mesmo momento:

Eu encontro abondas semellanzas entre ou que fai Covadonga e ou que fan as poetas galegas da súa xeración, e dou fe que non se puxeron de acordo. Encontro paralelismos temáticos e vitais entre ela e Yolanda Castañeiro, Emma Couceiro, Olga Novo e até Charo Pita.

Posibelmente Frías ten en mente algo que constitúe unha corrente pós-moderna na poesía actual. Un tipo de poesía descarnada, erótica, consciente da importancia da pulsión eros nos seres humanos e que expresa unha interioridade conflitiva sempre en relacións que esvaran coa alteridade. Frías defíneo así:

En calquera caso, o que máis se ve é un ti e un eu. Aparentemente mestúranse e conviven, mais se ollamos cunha pouca de calma, ou ti esvaece e sempre fica o eu, talvez un eu só, ergueito, soñador, insatisfeito e... leal. Por iso, unha serie de xogos forman parte do universo poético de Covadonga, como a cintura, que se constitúe nunha caste de universo en miniatura no que todo é posíbel.

Covadonga comparte con outros membros xa publicados na colección a publicación de textos en galego con textos en outras linguas integrándose así na alofonía, característica esencial para $O$ Roibén.

A outra incorporación é tamén feminina. Verónica Martínez (Valdoviño, 1976) publica Deshabitada e sen verdugo cunhas palabras preliminares a cargo de Manuel Pereira, poeta que, como vimos, comezara as súas publicacións comerciais nesta colección. A autora que ficara xa finalista no premio Letras de Cal co seu primeiro poemario Desterrada do meu corpo busca, no seu paso por Madrid, publicar nunha colección que conte co asentimento da flor e nata da cultu-

\footnotetext{
${ }^{13}$ Xavier Frías, no «Limiar» d'A soidade dos números primos.

${ }^{14}$ Ut supra.
} 
ra galega en Madrid e que a consolide dentro da panorama poética. Para explicar a súa maneira de facer, de entender o poético vexamos o que nos di nunha poética de recente publicación:

Lo que escribo es ante todo sincero.

Hablo de mundos oníricos, hirientes, cotidianos...

Suele tratarse de una poesía sensorial, emotiva, llena de imágenes, la pintura es referencia constante en la voz que habla, y de paisajes vividos y de saliva. Siempre hay un momento, dentro de ella, para las obsesiones, para el erotismo, para recordar con nostalgia el pasado y el futuro perdido. La emoción se vuelve concepto en el tacto. Es intenso el acercamiento a la esencia de lo visible, a la mezcla entre dolor y placer, a la pasión sin medida.

Normalmente escribo de un modo muy poco profesional, cuando ya no me resta otro modo de expresarme, y me sirve como catarsis, como evolución o involución pero hacia adelante, mirando de frente a la luz, a la luz devastadora desde la conciencia. ${ }^{15}$

Insiste a autora na sinceridade da súa expresión, no seu «pouco» contido literario posto que iso empurra ao finximento. A voz que fala, di, faise eco de «paisaxes vividas» sexan estas terreais ou humanas, e teñen unha repercusión sempre funda na súa poesía.

A partir desta publicación a colección vai progresivamente alongando as súas edicións até desaparecer. Luis Lua e Óscar Curieses publican a segunda entrega da tetraloxía anunciada con Ignicións en 2002 e Xavier Frías publica, tamén en 2002 Axarquía.

Despois a colección pasa por altibaixos, axustes e distintas denominacións até a súa refundación en Alcálima, o novo proxecto editorial que quere reconstruír dalgún modo o que foi o selo $O$ Roibén.

\section{A MODO DE CONCLUSIÓN}

A colección $O$ Roibén é, desde o punto de vista deste artigo, un ente fundamental no desenvolvemento da cultura galega fóra das fronteiras do estrito ámbito da Comunidade Autónoma de Galiza. Como vimos, asume o propósito de difundir a lingua, incidindo en a usar como vehículo de expresión cotián e artístico, recollendo, asemade, numerosas variantes dialectais de dentro e fóra de Galiza e contribuíndo á necesaria normalización lingüística das nosas linguas cooficiais.

En segundo lugar, reúne diversas xeracións de poetas en forma de conversacións, diálogos, escritura de prólogos e publicación de poemarios co que estabelece os nexos necesarios para a continuación, difusión e recepción crítica dun labor case sempre descoñecido e, a miúdo, infravalorado. Tende, ao mesmo

${ }^{15}$ Martínez, Verónica, «poética» en revista «Cuadernos del Ateneo», $\mathrm{n}^{\circ} 24$, Tenerife. 
tempo, as pontes que salvan as raias xeográficas entre a capital, Madrid e a Comunidade Autónoma de Galiza facendo mais fluídas as relacións entre creadores que utilizan a mesma lingua como vehículo de creación.

En terceiro lugar, e como fenómeno case privativo desta colección, recolle a obra de autores alógrafos, é dicir, autores que escollen a lingua galega non por vínculos afectivos se non estritamente acústicos ou estéticos, imprescindíbeis para vehicular a súa forma de ver, sentir e entender o mundo o cal enriquece aínda mais se colle a lingua de acollida.

En último lugar, a colección que nos ocupa descobre a obra de poetas soterrados ou que non coñecían a publicación comercial até publicaren na mesma. Deste modo, contribúen para a auxe imparábel das literaturas en linguas cooficiais que se produciu nestes últimos trinta anos. Fan, por tanto, parte da Historia.

\section{BIBLIOGRAFÍA}

Araguas, V. + Pereira, M. (ed.) (2001) En tránsito, poesía galega en Madrid, Ediciós do Castro, A Coruña.

Araguas, V. (2000) «Poetas galegos en Madrid», en Revistas das Letras, 296, suplemento d'O Correo galego, Santiago. [28-XII-2000]

Curieses, O. + Luna, L. (2000) Hidroemas, colección «O Roibén», Madrid, ACEF.

D’lom, Co. (2001) A soidade dous números primos, colección «O Roibén», Xuvia, ACEF.

Frías Conde, X. (ed.) (2010) Marés nos pousos de café. Mostra de poetas de expresión galega en Madrid, Pontevedra, El Taller del Poeta.

Frías, X. (2000) Azul e terra, poesía eonaviega (1997-1999), colección «O Roibén», Madrid, ACEF.

Frías, X. (2007) «Poesía galega contemporánea en Madrid: o grupo Bilbao», en Cuadernos del Ateneo, $\mathrm{n}^{\circ} 24$.

Galán, X. (2001) Alquimia soñada, colección «O Roibén», Madrid, ACEF.

González, S. + Veiguela, V. (2001) Simbiose, colección «O Roibén», Madrid, ACEF.

Pereira Valcárcel, M. (1998) Todo Morte, Colección O Roibén, Madrid, Edicións Rio

Pereira Valcárcel, M. (2000) Rosa íntima, Espiral Maior, A Coruña.

Regueiro, B. (2006) «Manuel Pereira Valcárcel: poesía da Experiencia na Galicia actual» en Madrygal (Madr.) 9. Universidad Complutense de Madrid.

Seara, Teresa (2001) «O Roibén: Literatura galega en Madrid» en Dorna, 27, pp. 163167.

Solla, C. (1999) Xábregho, colección «O Roibén», Xuvia, Edicións Rio Xuvia.

VV. AA. (1998) Carreiros, Mostra de poesía da Terra Eo-Navia en lingua galega, colección «O Roibén», Xuvia, Edicións Río Xuvia. 
VV. AA. (1998) Comercial, Poesía Galega en Madrid, colección «O Roibén», Xuvia, Edicións Río Xuvia.

Yáñez, R. (2000) Onte chovía. colección «O Roibén», Madrid, ACEF.

Yáñez, R. (2001) Lembranzas e olvidos dun estraño. colección «O Roibén», Madrid. ACEF. 
